\title{
ĐÁNH GIÁ KẾT QUẢ TRUNG HẠN PHÃU THUẠT GLENN THEO HAI HƯỚNG TRÊN BỆNH KHÔNG LỖ VAN BA LÁ
}

\author{
Kim vũ Phuoong*, Nguyễn văn Phan*
}

\section{TÓM TẮT}

58 bệnh nhân được phẫu thuật Glenn theo hai hướng bao gồm các trường hợp có hoặc không có tuần hoàn ngoài cơ thể với thời gian theo dõi trung bình $46.5 \pm 22.4$ tháng (ngắn nhất 10 tháng, dài nhất 92 tháng). Trong đó có 34 nam, 24 nữ, tuổi phẫu thuật từ 4 tháng đến 20 tuổi, cân nặng từ $3.5 \mathrm{~kg}$ đến $49 \mathrm{~kg}$. Tỷ lệ tử vong trong thời gian nằm viện là $(1.72 \%)$, không có tử vong muộn. Độ bão hoà oxy trung bình từ 74.7 $\pm 5.85 \%$ trước phẫu thuật tăng lên $89.45 \pm 1.78 \%$ khi xuất viện và lần theo dõi cuối $86.26 \pm 4.3 \%$. Áp lực trung bình động mạch phổi sau phẫu thuật $14.01 \pm$ $2.31 \mathrm{mmHg}$. Có 7 trường hợp được làm phẫu thuật Fontan với thời gian trung bình 62.85 tháng sau phầu thuật Glenn.

Phẫu thuật Glenn theo hai hướng trên bệnh không lổ van ba lá cho kết quả sớm và trung hạn tốt và là phẫu thuật ở giai đoạn trung gian nhằm chuẩn bị tốt nhất cho phẫu thuật Fontan tiếp theo.

Tù khóa: bệnh không lồ van 3 lá, phẫu thuật Glenn theo hai huớng.

\section{1. ĐẶT VẤN ĐỀ}

Bệnh không lỗ van ba lá là bệnh tim bẩm sinh tương đối hiếm gặp, chiếm $1-3 \%$ trong tổng số các bệnh tim bẩm sinh, được Kuhne đã mô tả lần đầu tiên vào năm 1906, được định nghĩa là tình trạng không có sự thông thương trực tiếp giữa nhĩ phải và thất phải. Nếu không có can thiệp ngoại khoa, chỉ $1 / 3$ bệnh nhân sống đến 1 tuổi và chỉ còn $10 \%$ sống đến 10 tuổi $[2,12]$. Tùy theo đặc điểm giải phẫu sinh lý, phần lớn trẻ sơ sinh không lỗ van ba lá cần thiết phải có một số can thiệp ngoại khoa để đem lại sự sống còn lâu dài và một trong những can thiệp đó là phẫu thuật Glenn. Phẫu thuật Glenn cổ điển được báo cáo lần đầu tiên vào năm 1958 bằng cách nối tĩnh mạch chủ trên vào đầu xa động mạch phổi phải, phẫu thuật này được sử dụng một thời gian dài sau đó, nhưng do một số bất lợi sau phẫu thuật Glenn cổ điển cũng như các yếu tố nguy cơ khi làm phẫu thuật Fontan. Đến năm 1972, Azollina đã cải tiến phẫu thuật Glenn cổ điển thành phẫu thuật Glenn theo hai hướng, bảo toàn sự hơp lưu của động mạch phổi phải và trái, giúp máu đi vào cả hai phổi. Phẫu thuật này làm cải thiện độ bão hoà oxy máu bằng cách tăng lưu lượng máu lên phổi hiệu quả, không làm tăng tải thể tích tâm thất, tránh biến dạng động mạch phổi, ngăn ngừa sự phát triển bệnh tắt nghẽn mạch máu phổi như khi làm thông nối chủ-phổi [4,12]. Ngày nay phẫu thuật Glenn theo hai hướng được xem là phẫu thuật tạm thời áp dụng cho bệnh không lổ van ba lá cũng như các bệnh tim bẩm sinh có tâm thất chung khác, phẫu thuật có thể được thực hiện lần đầu hoặc giai đoạn thứ hai sau phẫu thuật thông nối chủ-phổi hoặc phẫu thuật xiết thân động mạch phổi trước khi làm phẫu thuật Fontan.

\section{2. ĐỐI TƯợNG VÀ PHƯơng PHÁP NGHIÊN CỨU}

Đây là nghiên cứu hồi cứu mô tả với mục tiêu đánh giá kết quả trung hạn những trường hợp được làm phẫu thuật Glenn theo hai hướng trên bệnh không lổ van ba lá. Thông tin bệnh nhân trước và sau phẫu thuật được ghi nhận qua hồ sơ bệnh án, tất cả các trường hợp sống sót được tái khám định kì 3-6 tháng và được kiểm tra siêu âm tim, $\mathrm{SpO} 2, \mathrm{Hct}, \ldots$ và các cận lâm sàng khác nếu cần thiết. Tất cả bệnh nhân đều được sử dụng kháng đông sau phẫu thuật (Aspirin $5 \mathrm{mg} / \mathrm{kg}$ ).

Phẫu thuật Glenn theo hai hướng là phẫu thuật tạm thời được áp dụng cho bệnh không lổ van ba lá và các bệnh tim bẩm sinh có tâm thất chung khác nhằm chuẩn bị tốt nhất cho phẫu thuật Fontan tiếp theo, phẫu thuật có thể được thực hiện lần đầu hoặc lần thứ hai sau phẫu thuật thông nối chủ-phổi hay xiết thân động mạch phổi. Từ tháng 3/2006 đến tháng 3/2014, có 58 trường hợp bệnh không lổ van ba lá đã được phẫu thuật Glenn theo hai hướng tại bệnh viện tim Tâm Đức và Viện Tim TP.HCM, trong đó có 2 trường hợp đã được phẫu thuật Blalock-taussig cải tiến, 1 trường hợp xiết thân động mạch phổi trước đó. Trong tất cả 58 trường hợp, nam có 34 trường hợp chiếm $58.6 \%$, nữ có 24 trường hợp chiếm $41.4 \%$, tuổi phẫu thuật trung bình 56 tháng (nhỏ nhất 4 tháng, lớn nhất 20 tuổi), cân nặng lúc phẫu thuật trung bình $14.1 \mathrm{~kg}$ (nhỏ nhất $3.5 \mathrm{~kg}$, lớn nhất $39 \mathrm{Kg}$ ), độ bão hoà oxy máu ngoại vi (SpO2) trước phẫu thuật trung bình $74.7 \pm$ $5.8 \%$ (thấp nhất $50 \%$, cao nhất $82 \%$ ), dung tích hồng cầu (Hct) trước phẫu thuật trung bình $66.9 \pm 7.6 \%$ (thấp nhất $46 \%$, cao nhất $81.6 \%$ ).

\footnotetext{
* Viện Tim Thành phố Hồ Chí Minh

Người chịu trách nhiệm khoa học: PGS.TS Nguyễn Văn Phan

Ngày nhận bài: 20/07/2015 - Ngày Cho Phép Đăng: 20/08/2015

Phản Biện Khoa học: PGS.TS. Đặng Ngọc Hùng PGS.TS. Bùi Đúc Phú
} 
Phẫu thuật Glenn theo hai hướng được thực hiện qua đường mở xương ức với việc có thể sử dụng tuần hoàn ngoài cơ thể hoặc không sử dụng tuần hoàn ngoài cơ thể, nếu có kết hợp với việc sửa chữa các bất thường khác trong tim thì tuần hoàn ngoài cơ thể luôn được sử dụng và trong trường hợp có hai tĩnh mạch chủ trên, nếu không kết hợp sửa chữa các bất thường trong tim thì việc sử dụng tuần hoàn ngoài cơ thể là không cần thiết. Miệng nối tận-bên giữa tĩnh mạch chủ trên với động mạch phổi phải được thực hiện với việc sử dụng chỉ 6.0 đơn sợi có thể tiêu được và khâu mũi liên tục, đối với chỉ không tan ta khâu mũi liên tục ở một nữa mặt dưới và khâu mũi rời ở mặt trên. Tĩnh mạch đơn và ống động mạch được cột lại ở tất cả các trường hợp, nguồn máu từ tâm thất lên động mạch phổi được để lại ở tất cả các trường hợp (nếu có) nhưng được kiểm soát thông qua việc đánh giá áp lực động mạch phổi và $\mathrm{SpO} 2$ ngay sau phẫu thuật, các nguồn máu lên phổi khác (thông nối chủphổi, tuần hoàn bàng hệ) được loại trừ trước hoặc trong phẫu thuật.

\section{KẾT QUẢ}

Trong tất cả 58 trường hợp, có 20 trường hợp sử dụng tuần hoàn ngoài cơ thể chiếm tỉ lệ $34.48 \%, 34$ trường hợp không sử dụng tuần hoàn ngoài cơ thể chiếm tỉ lệ $65.52 \%$. Các phẫu thuật khác phối hợp trong lúc phẫu thuật Glenn theo hai hướng được mô tả ở bảng 1 .

Bảng 1: Các phẫu thuật phối hợp khi làm phẫu thuật BGS:

\begin{tabular}{|l|c|c|}
\hline \multicolumn{1}{|c|}{ Các phẫu thuật khác } & $\begin{array}{c}\text { Bệnh } \\
\text { nhân }\end{array}$ & $\begin{array}{c}\text { Tỷ lệ } \\
(\%)\end{array}$ \\
\hline Nối TMCT vào ĐMP hai bên & 12 & 20.69 \\
\hline Mở rộng thông liên nhĩ & 8 & 13.79 \\
\hline Mở rộng thông liên thất & 1 & 1.72 \\
\hline Cột ông động mạch & 40 & 68.97 \\
\hline Sửa van hai lá & 2 & 3.44 \\
\hline Mở rộng nhánh động mạch phổi & 1 & 1.72 \\
\hline Xiết thân ĐMP & 2 & 3.44 \\
\hline
\end{tabular}

\subsection{Kết quả sớm}

Ở hậu phẫu, nhóm bệnh nhân nghiên cứu có thời gian thở máy là $9.83 \pm 5.33$ giờ $(3-26$ giờ), thời gian nằm điều trị tại hồi sức là $1.33 \pm 0.73(1-4$ ngày), Có 1 trường hợp tử vong, chiếm tỷ lệ $1 / 58(1.72 \%)$. Trường hợp tử vong là bệnh nhân nam, 8 tháng tuổi, cân nặng 4kg, được phẫu thuật Glenn theo hai hướng, rút nội khí quản giờ thứ 25 sau phẫu thuật, nằm hồi sức 3 ngày, ra khoa điều trị được 3 ngày (ngày hậu phẫu thứ 6) bệnh nhân nhập lại hồi sức do viêm phổi không đáp ứng với kháng sinh phổ rộng và tử vong ngày hậu phẫu 16. Một số biến chứng khác trong quá trình theo dõi hậu phẫu được mô tả trong bảng 2. Sự thay đổi độ bão hoà oxy máu và dung tích hồng cầu trước và sau phẫu thuật được mô tả ở bảng 3, áp lực động mạch phổi trung bình sau phẫu thuật $14.01 \pm 2.31 \mathrm{mmHg}$. Ngoài ra đánh giá siêu âm lúc xuất viện, không có trường hợp nào hẹp miệng nối sau phẫu thuật và đo điện tâm đồ không có trường hợp nào rối loạn nhịp.

\section{Bảng 2: Biến chưng hậu phẫu}

\begin{tabular}{|l|c|c|}
\hline \multicolumn{1}{|c|}{ Biến chứng } & $\begin{array}{c}\text { Bệnh } \\
\text { nhân }\end{array}$ & $\begin{array}{c}\text { Tỷ lệ } \\
\text { (\%) }\end{array}$ \\
\hline Tràn dịch dưỡng trấp & 3 & 5.17 \\
\hline Hội chứng cung lượng tim thấp & 2 & 3.45 \\
\hline $\begin{array}{l}\text { Suy thận cấp cần phải thẩm phân } \\
\text { phúc mạc }\end{array}$ & 1 & 1.72 \\
\hline Viêm phổi & 2 & 3.45 \\
\hline Tràn dịch màng tim cần phải dẫn lưu & 2 & 3.45 \\
\hline Tràn dịch màng phồi cần phải dẫn lưu & 1 & 1.72 \\
\hline Chảy máu cần cầm máu lại & 4 & 6.9 \\
\hline Hội chứng tĩnh mạch chủ trên & 1 & 1.72 \\
\hline
\end{tabular}

Bảng 3: So sánh Hct, SpO2 truoớc và sau phẫu thuật .

\begin{tabular}{|l|c|c|c|}
\hline Thông số & $\begin{array}{c}\text { Trước } \\
\text { phẫu thuật }\end{array}$ & $\begin{array}{c}\text { Sau } \\
\text { phẫu thuật }\end{array}$ & p \\
\hline Hct (\%) & $66.98 \pm 7.66$ & $43.2 \pm 5.14$ & 0.000 \\
\hline SpO2 (\%) & $74.7 \pm 5.83$ & $89.45 \pm 1.78$ & 0.000 \\
\hline
\end{tabular}

Bảng 3 cho thấy dung tích hồng cầu và độ bão hoà oxy máu trước và sau phẫu thuật thay đổi có ý nghĩa thống kê $(\mathrm{p}<0.001)$.

\subsection{Kết quả trung hạn}

Chúng tôi đánh giá kết quả trung hạn với thời gian theo dõi trung bình $46.5 \pm 22.4$ tháng, thời gian theo dõi ngắn nhất 10 tháng, thời gian theo dõi dài nhất 92 tháng. Nhìn chung không có trường hợp nào tử vong, có 7 trường hợp được làm phẫu thuật Fontan (12.28\%), thời gian từ lúc phẫu thuật Glenn theo hai hướng đến lúc phẫu thuật Fontan trung bình 62.85 tháng. Có 2 trường hợp phải đóng tuần hoàn bàng hệ chủ-phổi trước khi làm phẫu thuật Fontan, sự thay đồi độ bão hoà oxy máu và dung tích hồng cầu sau phẫu thuật và lần theo dõi cuối được mô tả ở bảng 4. Không phát hiện trường hợp nào hẹp miệng nối hay rối loạn nhịp trong quá trình theo dõi.

Bảng 4. So sánh Hct, SpO2 sau phẫu thuật và lần theo dõi cuối

\begin{tabular}{|l|c|c|c|}
\hline \multicolumn{1}{|c|}{ Thông số } & $\begin{array}{c}\text { Sau phẫu } \\
\text { thuật }\end{array}$ & $\begin{array}{c}\text { Theo dõi } \\
\text { cuối }\end{array}$ & p \\
\hline Hct $(\%)$ & $43.2 \pm 5.14$ & $51.23 \pm 7.52$ & 0.000 \\
\hline SpO2 (\%) & $89.45 \pm 1.78$ & $86.26 \pm 4.03$ & 0.000 \\
\hline
\end{tabular}


Theo dõi bệnh nhân qua những lần tái khám nghi nhận dung tích hồng cầu, và độ bão hoà oxy máu, từ bảng 4 ta thấy sự thay đổi $\mathrm{SpO} 2$ và $\mathrm{Hct}$ sau phẫu thuật và ở lần theo dõi cuối thay đổi có ý nghĩa thống kê $(\mathrm{p}<0.001)$.

\section{BÀN LUẬN}

Phẫu thuật Glenn theo hai hướng được sử dụng như là phẫu thuật tạm thời cho bệnh không lổ van ba lá cũng như các bệnh tim bẩm sinh có tâm thất chung khác để chuẩn bị cho phẫu thuật Fontan sau này, phẫu thuật này được cho là có các ưu điểm là giảm tải thể tích thất trái, phòng ngừa sự biến dạng động mạch phổi cũng như bệnh tắt nghẽn mạch máu phổi so với phẫu thuât thông nối chủ-phổi $[12,17]$. Theo tác giả Hawkins tỉ lệ tử vong ở nhóm bệnh nhân được phẫu thuật Fontan mà không làm phẫu thuật Glenn theo hai hướng trước đó $(10 \%)$, cao hơn những trường mà bệnh nhân hợp được làm phẫu Glenn theo hai hướng trước đó $(4.8 \%)$ [11].

Chắc chắn không có sự thống nhất về các tiêu chuẩn cho phẫu thuật Glenn theo hai hướng, hầu hết các tác giả cho rằng: áp lực trung bình động mạch phổi nên $<18 \mathrm{mmHg}$, lý tưởng $<15 \mathrm{mmHg}$ với kháng lực mạch máu phổi < 2 đơn vị Wood $[12,17]$. Mặc dù có một số hướng dẫn chung về đường kính động mạch phổi có thể chấp nhận cho phẫu thuật Glenn theo hai hướng $[14,18]$, tuy nhiên các biến dạng động mạch phổi như: thiếu sản động mạch phổi, gián đoạn động mạch phổi, hẹp phần xa động mạch phổi vẫn còn là yếu tố nguy cơ cho kết quả phẫu thuật sau này. Phẫu thuật Glenn theo hai hướng có thể thực hiện ở tuổi rất nhỏ và cho tỉ lệ tử vong thấp [15]. Theo tác giả Gross và cộng sự, những bệnh nhân được phẫu thuật khi đã lớn hơn 3,9 tuổi và diện tích da bề mặt cơ thể lớn hơn $0.65 \mathrm{~m} 2$ thì có sự gia tăng đáng kể tình trạng thiếu oxy máu nặng, điều này được cho là do khi cơ thể lớn hơn, lưu lượng máu ở phần trên so với phần dưới cơ thể giảm đáng kể so với lúc nhỏ [10]. Tuy nhiên, hầu hết các tác giả cho rằng phẫu thuật Glenn theo hai hướng nên thực hiện ở giai đoạn từ 3-6 tháng tuổi để đạt được lợi ích tối đa $[12,17,16]$. Phẫu thuật Glenn theo hai hướng làm cải thiện độ bão hoà oxy máu và làm giảm dung tích hồng cầu đáng kể sau phẫu thuật [11, $6,17]$, cải thiện độ bão hoà oxy máu do lưu lượng máu lên phổi hiệu quả, mặt khác khi dung tích hồng cầu giảm sẽ làm độ nhớt của máu giảm, góp phần làm tăng lưu lượng máu lên phổi [17].

Mặc dù phẫu thuật Glenn theo hai hướng đã được sử dụng rộng rãi cho bệnh không lổ van ba lá cũng như các bệnh tim bẩm sinh có tâm thất chung, tuy nhiên có một số vấn đề liên quan đến kết quả lâu dài của phẫu thuật như: tím ngày càng tăng, độ bão hoà oxy máu càng giảm, sự hình thành các tuần hoàn bàng hệ chủ-phổi, tuần hoàn bàng hệ tĩnh mach hệ thốngtĩnh mạch phổi, dò động - tĩnh mạch trong phổi và sự thay đổi kích thước động mạch phổi sau phẫu thuật. Một số tác giả cho rằng các vấn đề này có thể giảm hoặc loại bỏ bằng cách để lại nguồn máu từ tâm thất lên động mạch phổi nhằm tăng lưu lượng và thể tích máu lên phổi, tạo dòng máu có mạch đập và máu từ tĩnh mạch gan được đưa lên cả hai phổi $[5,7,19]$. Một số tác giả khác cho rằng có xu hướng cải thiện sự sống còn khi các nguồn máu phụ được loại bỏ, trong khi các bệnh nhân có nguồn máu phụ lên phổi sẽ có nguy cơ, tràn dịch màng phổi, thời gian nằm viện kéo dài, áp lực động mạch phổi sau phẫu thuật cao và tràn dịch dưỡng trấp phát triển muộn [13].

Trong nghiên cứu của chúng tôi, tất cả các trường hợp có nguồn máu từ tâm thất lên động mạch phổi (nêu có) đều được để lại nhưng có kiểm soát (áp lực trung bình động mạch phổi sau phẫu thuật không lớn hơn $16 \mathrm{mmHg}$ [7]), các nguồn máu lên phổi khác (ống động mạch, tuân hoàn bàng hệ, thong nối chủ-phối) được loại bỏ với mục đích không làm tăng tải thể tích thất trái, cải thiện chức năng cơ tim, giảm độ hở van nhĩ thất [8]. Áp lực trung bình động mạch phổi sau phẫu thuật $14.01 \pm 2.31 \mathrm{mmHg}$, áp lưc này là lý tưởng sau phẫu thuật Glenn theo hai hướng. Tuy nhiên chúng tôi có 2 trường hợp áp lực $>18 \mathrm{mmHg}$, cả 2 trường hợp này chúng tôi tiến hành xiết thân động mạch phổi sau đó.Theo bảng 3 và bảng 4 , ta thấy độ bão hoà oxy máu cải thiện đáng kể sau phẫu thuật $(\mathrm{p}<0.001)$ và dung tích hồng cầu cũng giảm đáng kể sau phẫu thuật $(\mathrm{p}<0.001)$. Tuy nhiên sau quá trình theo dõi, độ bão hoà oxy có xu hướng giảm và dung tích hồng cầu ngày càng tăng $(\mathrm{p}<0.001)$. Trong tổng số 58 trường hợp nghiên cứu, chúng tôi có 12 trường hợp biến chứng sớm sau phẫu thuật chiếm tỉ lệ $20.9 \%$ (bảng 2), một số trường hợp có nhiều hơn một biến chứng. Theo tác giả Chang [8], tỉ lệ các biến chứng sau phẫu thuật như hội chứng tĩnh mạch chủ trên, hội chứng cung lượng tim thấp, rối loạn nhịp chiếm tỉ lệ cao, trong khi đó theo nghiên cứu của chúng tôi và một số tác giả $[7,11]$ thì tỉ lệ các biến chứng này rất thấp. Tỉ lệ chảy máu phải cầm lại trong nghiên cứu của chúng tôi $6.9 \%$, tỉ lệ này tương đương với tác giả Xie Bin [19] 6\%. Nhìn chung trong nghiên cứu của chúng tôi tỉ lệ các biến chứng sau phẩu thuật tương đương hoặc thấp hơn các tác giả khác và theo một số tác giả $[9,13]$ các biến chứng này không làm kéo dài thời gian thở máy cũng như thời gian nằm hồi sức.

Kết quả trung hạn của chúng tôi nhìn chung không có trường hợp nào tử vong, không có trường hợp nào hẹp miệng nồi qua đánh giá bằng siêu âm tim, không có trường hợp nào rối loạn nhịp tim trên điện tâm đồ. Có 7 trường hợp được làm phẫu thuật Fontan $(12.28 \%)$, các bệnh nhần này đều có lâm sàng tím ngày càng tăng, độ bão hoà oxy máu thấp và dung tích hồng cầu cao. Thời gian từ lúc phẫu thuật Glenn theo 
hai hướng đến lúc phẫu thuật Fontan trung bình 62.85 tháng (36- 82 tháng). Có 2 trường hợp được làm phẫu Fontan lúc 36 tháng sau phẫu thuật Glenn theo hai hướng, cả 2 trường hợp này đều được chẩn đoán trước phẫu thuật là loại Ia (không có nguồn máu từ tâm thất lên động mạch phổi). Có 2 trường hợp được chẩn đoán có tuần hoàn bàng hệ chủ-phổi, cân phải đóng bằng thông tim trước khi làm phẫu thuật Fontan.

Trong nghiên cứu của chúng tôi có một trường hơp tử vong sau phẫu thuật chiếm tỉ lệ $1.72 \%$, tỉ lệ này tương đương với tác giả Xie Bin 1.8\% [19] và thấp hơn một số tác giả Reddy 4.8\% [16], Hawkins 5.3\% [11], Berdat 5.7\% [5]. Trường hợp tử vong này không liên quan đến kỹ thuật mổ, bệnh nhân sau phẫu thuật được rút nội khí quản và chuyển ra khoa điều trị, sau đó chuyển vào hồi sức do viêm phổi, và tử vong ngày hậu phẫu thứ 16 với chẩn đoán viêm phổi không đáp ứng với điều trị kháng sinh phổ rộng.

\section{KẾT LUẬN}

Nghiên cứu 58 trường hợp bệnh không lổ van ba lá đã được làm phẫu thuật Glenn theo hai hướng tại bệnh viện tim Tâm Đức và Viện Tim TP.HCM từ tháng 3/2006 đến tháng 3/2014, chúng tôi rút ra kết luận: phẫu thuật Glenn theo hai hướng là một phẫu thuật tạm thời được lựu chọn tốt cho bệnh không lổ van ba lá với kết quả phẫu thuật sớm và trung hạn tốt. Phẫu thuật này làm giảm triệu chứng, cải thiện độ bão hoà oxy máu, cải thiện chất lượng cuộc sống và giảm tỉ lệ tử vong khi phẫu thuật Fontan. Ngoài ra, với các bệnh nhân có nguồn máu từ tâm thất lên động mạch phổi thì tình trạng tím tăng chậm hơn, độ bão hoà oxy máu giảm chậm hơn, nên thời gian từ phẫu thuật Glenn theo hai hướng đến phẫu thuật Fontan kéo dài hơn.

\section{TÀI LIỆU THAM KHẢO}

1. Ngô Quốc Hùng (2012), "Đánh giá kết qua phẫu thuật nối tĩnh mạch chủ trên vào động mạch phổi tại viện tim TPHCM từ 01/2004 đến 12/2010" Luận vắn thạc sĩ $y$ hoc, TP.HCM

2. Phạm Nguyễn Vinh (2003), "Không lỗ van ba lá", siêu âm tim và bệnh lý tim mạch, NXB y học, tập 1, tr.205-214.

3. Phan Kim Phương, Nguyễn Minh Trí Viên, Đặng Hữu Danh, Phan Ngọc Truyền (2010), "Phẫu thuật nối tĩnh mạch chủ trên - động mạch phồi thông ra hai hướng tại Viện tim TP HCM: Có gì mới?",Tạp Chi Y Hoc, tai trang web:http://www.phauthuattim.org.vn

4. Azzolina G, Eufrate S, Pensa P (1972), "Tricuspid atresia: Experience in surgical management with a modified cavopulmonary anastomosis", Thorax, 27, pp. 111-115.
5. Berdat et al (2005), " Additional pulmonary blood flow has no adverse effect on outcome after bidirectional cavopulmonary anastomosis", Ann Thorac Surg, 79, pp.29-37

6. Bridges ND, Jonas RA, Mayer JE, Flanagan MF, Keane JF, Castan ${ }^{\sim}$ eda AR (1990), "Bidirectional cavopulmonary anastomosis as interim palliation for high-risk Fontan candidates. Early results", Circulation, 82 (Suppl 4), pp.170-176.

7. Caspi J et al (2003), "Effects of controlled antegrade pulmonary blood flow on cardiac function after Bidirectional cavopulmonary anastomosis", Ann Thorac Surg, 76, pp. 1917-1921.

8. Chang AC et al (1993), "Early bidirectional cavopulmonary shunt in young infants: Postoperative course and early results". Circulation, 88, pp. II149-158.

9. Frommelt M, Frommelt PC, Berger S, et al (1995), "Does an additional source of pulmonary blood flow alter outcome after a bidirectional cavopulmonary shunt?", Circulation, 192, (Suppl 2), pp. 240-244.

10. Gross GJ, Jonas RJ, (1994), "Maturational and hemodynamic factors predic- tive of increased cyanosis following bidirectional cavopul- monary anastomosis", Am J Cardiol, 74, pp.705-709.

11. Hawkins JA et al (1993), "Mid-term results after bidirectional cavopulmonary shunts", Ann Thorac Surg, 56, pp. 833-837.

12. Kirklin J.W, Barrat- Boyes B.G (2003), "Tricuspid Atresia and Management of Single-Ventricle Physiology", Cardiac Surgery, Churchill Livingstong, 3rd edition, volume 2, (27), pp. 1113- 1176.

13. Mainwaring et al (1999), "Effect of Accessory Pulmonary Blood Flow on Survival After the Bidirectional Glenn Procedure", Circulation, 100 [suppl II], pp. II-151-II-156.

14. Pridjian AK, Mendelsohn AM, Lupinetti FM, et al (1993), "Usefulness of the bidirectional Glenn procedure as staged recon- struction for the functional single ventricle", Am J Cardiol, 71, pp. 959-962.

15. Reddy VM et al (1995), "Primary bidirectional superior cavopulmonary shunt in infants between 1 and 4 months of age", Ann Thorac Surg, 59, pp. 1120-1126.

16. Reddy et al (1997), "Outcomes After Bidirectional Cavopulmonary Shunt in Infants less than 6 months old", JACC Vol. 29, No. 6, pp. 1365-7130.

17. Robert MF et al (1998), "The physiology of the Bidirectional Cavopulmonary Connection", Ann Thorac Surg, vol.66, pp. 664-667.

18. S.Subramanian et al (1965), "Palliative surgery in tricuspid atresia", Circulation, Volume XXXII.

19. Xie B (2001), "Bidirectional Glenn shunt: 170 cases", Asian Cardiovasc Thorac Ann, vol. 9, pp. 196-199. 